\title{
О СУЩНОСТИ ИНТРАПРЕНЕРСТВА И НЕОБХОДИМОСТИ ЕГО РАЗВИТИЯ В УСЛОВИЯХ ГЛОБАЛИЗАЦИИ
}

\begin{abstract}
АНнотАция. В настоящее время в России активизировался процесс развития предпринимательства. На основе анализа российского и зарубежного опыта обосновывается необходимость взаимодействия предприятий крупного, среднего и малого бизнеса. В статье проанализирована такая форма взаимодействия крупного и малого бизнеса как интрапренерство. Рассматриваются точки зрения различных авторов на понятие «внутрифирменное предпринимательство». Высказывается точка зрения автора статьи на это понятие. Исследуются основные концептуальные подходы к интрапренерству. Объединение возможностей малого и крупного бизнеса обеспечивает эффективное функционирование экономики в условиях глобализации. В статье рассмотрены подходы $\mathrm{\kappa}$ пониманию интрапренерства, проанализированы социально-психологические, экономические и технические предпосылки возникновения внутрифирменного предпринимательства — интрапренерства, а также современные тенденции его развития, также рассмотрены преимущества и недостатки проектов в малом бизнесе. Исследуется влияние интрапренерства на әффективность деятельности организации.

кЛючЕВыЕ словА. Крупный бизнес; малый бизнес; интрапренерство; межфирменное предпринимательство; глобализация.

ИНФОРМАЦИЯ О СТАТЬЕ. Дата поступления 13 сентября 2017 г.; дата принятия к печати 19 декабря 2017 г.; дата онлайн-размещения 29 декабря 2017 г.
\end{abstract}

G. V. Guseva

Baikal State University, Irkutsk, Russian Federation

\section{ON THE MATTER OF ENTREPRENEURSHIP AND THE NEED FOR ITS DEVELOPMENT IN THE CONTEXT OF GLOBALIZATION}

\begin{abstract}
The process of entrepreneurship development has become active nowadays in Russia. The necessity of interaction between big, mid-sized and small business enterprises is substantiated, based on the analysis of Russian and foreign experience. The article analyzes such a form of interaction between big and small businesses as the entrepreneurship. Various authors' views on the concept of «intra-company entrepreneurship» are observed. The author's point of view on this concept is expressed. The basic conceptual approaches to entrepreneurship are examined. Cooperation of capabilities of small and large businesses ensure an effective functioning of the economy in the context of globalization. The article considers approaches for understanding entrepreneurship, analyzes socio-psychological, economic and technical prerequisites for emergence of intra-company entrepreneurship, as well as the current trends of its development, and also it considers the advantages and disadvantages of projects in a small business. The influence of entrepreneurship on the effectiveness of the organization's activities is examined.
\end{abstract}

KEYWORDS. Large business; small business; entrepreneurship; intra-company relations; globalization.

ARTICLE INFO. Received September 13, 2017; accepted December 19, 2017; available online December 29, 2017.

C развитием рыночной экономики в стране осуществляется большое количество социально-экономических преобразований. Для современной экономической системы России одним из ключевых условий устойчивого развития является использование принципов предпринимательской экономики. В теоретических иссле-

(C) Г. В. Гусева, 2017

\section{Baikal Research Journal}


дованиях в настоящее время уделяется серьезное внимание предпринимательству как способу ведения дел на самостоятельной основе и эффективным формам взаимодействия крупного и малого бизнеса, оказывающим серьезное влияние на качество экономического роста. Одной из наиболее эффективных форм взаимодействия на сегодняшний день, как показывает мировая практика, является интрапренерство. Исходя из этого, представляется актуальным изучение предпосылок возникновения интрапренерства и необходимости его внедрения в компаниях нашей страны.

Понятие «интрапренерство» возникло из сочетания двух слов: «enterpris» предприятие или предпринимательство и латинского префикса «intra» — внутри. Таким образом, данное понятие означает «внутрифирменное предпринимательство». Термин был введен в оборот американским исследователем Г. Пиншо. Он сформулировал данную категорию как современную разновидность компании, представляющую собой самоорганизующуюся систему, чьи подразделения и работающие в них люди имеют невиданные, по сравнению с современными корпоративными структурами, возможности и свободу действий [1].

Трактовка интрапренерства отечественными специалистами дается как с позиции процесса, так и с позиции структуры. По мнению Г.Л. Багиева и А.Н. Асаула: «Под интрапренерством понимается развитие духа предпринимательства и его осуществление внутри существующего предприятия. Интрапренерство заключается в том, что на действующем предприятии, выпускающем определенную продукцию (работу или услугу) создаются условия для выдвижения новаторских предпринимательских идей:

- выделяются ресурсы - интракапитал - для их реализации;

- оказывается всесторонняя помощь для для реализации идеи и ее практического использования» [2].

По мнению О. В. Чистяковой, интрапренерство представляет собой метод управления организацией, основанный, главным образом, на инициативах исполнителей, а не администрировании [3, с. 67]. Данный подход, на наш взгляд, является весьма верным, так как отражает личностно-ориентированную направленность внутрифирменного предпринимательства.

Интерес к интрапренерству объясняется рядом важных изменений, произошедших в США в 80-90x гг. прошлого века как в социальной сфере, так и в области бизнеса, которые сегодня стали весьма актуальны для нашей страны. В социальной сфере растет интерес к тому, чтобы заниматься своим собственным делом, делать это, исходя их своих интересов, на собственных условиях. Индивиды, которые верят в свой талант, все больше стремятся к самостоятельной деятельности. Эта жажда ответственности и сильное стремление к самовыражению привели к тому, что сотрудники желают заполучить больше самостоятельности в рамках организационной структуры. Если такая свобода им не обеспечивается, то у них, как правило, развивается неудовлетворенность организацией, что может привести к снижению производительности и даже к уходу в поисках условий для самореализации. Стремление к самостоятельной деятельности и желание обрести свободу немедленно привели в настоящее время к большей неудовлетворенности в организациях с разветвленной структурой, чем это было в прошлом. Если организация не обеспечивает в полной мере выполнение этих условий, то люди начинают заниматься поисками таких организаций, которые их обеспечивают. Интрапренерство является инструментом, который облегчает решение этой задачи людям, работающим в данной организации и задумывающимся над тем, что следует изменить, а что сделать совершенно иначе.

Наряду с ростом влияния социальных факторов усиливается давление, оказываемое на интрапренерство со стороны бизнеса. Чрезвычайно высокая конкурен-

\section{Baikal Research Journal}

электронный научный журнал Байкальского государственного университета 
ция как внутри страны, так и за ее пределами заставила американские компании наращивать усилия в производстве новых продуктов, диверсификации и повышении производительности [4].

Данные явления в социальной и экономической сфере сегодня весьма актуальны. Однако, на наш взгляд, это далеко не все предпосылки необходимости внедрения принципов интрапренерства в предприятиях нашей страны. Структурируем предлагаемые нами факторы, объединив их в таблице.

\section{Предпосылки возникновения интрапренерства в РФ}

\begin{tabular}{|l|l|}
\hline \multicolumn{1}{|c|}{ Сфера влияния } & \multicolumn{1}{|c|}{ Факторы влияния } \\
\hline $\begin{array}{l}\text { Сфера управление (социаль- } \\
\text { но-психологический аспект) }\end{array}$ & $\begin{array}{l}\text { Тенденция развития образования и самосознания людей } \\
\text { Социальные аспекты мотивации деятельности }\end{array}$ \\
\hline Технико-экономическая сфера & $\begin{array}{l}\text { Макроуровень: } \\
\text { Тенденции глобализации мировой экономики } \\
\text { Тенденции ускорения научно-технического прогресса } \\
\text { Обострение международной конкуренции } \\
\text { Мезоуровень: } \\
\text { Поиск конкурентных преимуществ } \\
\text { Микроуровень } \\
\text { Сфера государственного регули- } \\
\text { рования }\end{array}$ \\
\hline
\end{tabular}

Социально-психологические предпосылки формирования интрапренерства были обусловлены существенным качественным повышением уровня жизни людей. Базовые потребности человека, связанные с выживанием и обеспечением физической безопасности, начали стабильно удовлетворяться. Следовательно, на первый план стали выходить такие потребности, как причастность, уважение и самореализация. Так, например, первичным для человека стал вопрос самореализации, решение которого невозможно без обеспечения возможностей для карьерного роста и без поддержания серьезного уровня мотивации сотрудников со стороны бизнес-структур. Так и сформировались такие предпосылки возникновения интрапренерства, как тенденция развития образования и самосознания людей и социальные аспекты мотивации деятельности.

Так, общие тенденции развития современного образования во многом нацелены на универсализацию систем образования в международном аспекте, на обеспечение рынка труда необходимой актуальной квалификационной рабочей силой, на профилизацию, предусматривающую развитие творческих способностей и творческого мышления, стимулирование познавательной деятельности, которое осуществляется за счёт повышения уровня проблемной образовательной ситуации.

Определим следующие наиболее значимые тенденции развития современного образования: гуманизация, предполагающая большое внимание к личности, её психологии, интересам; гуманитаризация, означающая усиление внимания к изучению общественных и гуманитарных дисциплин; интернационализация, ориентированная на максимизацию сближения национальных образовательных систем; компьютеризация, направленная на использование новых современных технологий обучения; демократизация, ориентированная на общедоступность образования; непрерывность, обеспечивающая способность работника к быстрым переключениям на новые виды работ, на новые технологии в условиях НТП; рост продолжительности образования, направленный на удлинение сроков обучения ${ }^{1}$.

${ }^{1}$ Ведущие тенденции развития образования в современном мире. URL: http://ifreestore.net/1238/5.

\section{Baikal Research Journal}

электронный научный журнал Байкальского государственного университета 
Социальные аспекты мотивации деятельности проявляются в процессе удовлетворения работниками своих потребностей и ожиданий в выбранной ими работе, осуществляемый в результате реализации их целей, согласованных с целями и задачами предприятия, и одновременно с этим это комплекс мер, применяемых со стороны субъекта управления для повышения эффективности труда работников. Развитие интрапренерства способно подействовать на выстраивание грамотной мотивационной политики, выстраиваемой руководством компании, на основании известных им потребностей и интересов работников, а также обеспечить стимулирование труда, всегда дополняющее мотивационную политику, и являющееся средством удовлетворения конкретных потребностей работника, по большей части материальных [5]. Например, В. Н. Якимов выделяет следующие формы стимулирования сотрудников: бонусы участия в акционерном капитале, планы дополнительных выплат, заработная плата, участие в прибылях [6, с. 63.]. Так, в создании надлежащих условий жизнедеятельности сотрудников отражается эффективность социальной инфраструктуры компании [7].

Технико-экономические предпосылки возникновения интрапренерства предлагается разбить на следующие категории: макроуровень, мезоуровень и микроуровень.

На макроуровне предпосылки развития интрапренерства связаны, главным образом, с тенденциями глобализации мировой экономики и ускорением научно-технического прогресса. Такие явления, как научно-технический прогресс в области транспорта и средств связи и коммуникации, углубление международного разделения труда, либерализация торговли и иные формы экономической либерализации, вызвавшие ограничение политики протекционизма и сделавшие мировую торговлю более свободной, а также важнейший для экономики сегодняшних дней феномен транснационализации привели к так называемому сокращению экономического расстояния между странами, что обусловило становление глобализации.

Глобализация сказывается на экономике всех стран. Она затрагивает производство товаров и услуг, использование рабочей силы, инвестиции, технологии и их распространение из одних стран в другие. Все это в конечном итоге отражается на эффективности производства, производительности труда и конкурентоспособности. Именно глобализация вызвала обострение международной конкуренции.

Процесс глобализации экономики ускорился в последние десятилетия, когда различные рынки, в частности, капитала, технологии и товаров, а в известной степени и труда, становились все более взаимосвязанными и интегрированными в многослойную сеть ТНК. Хотя определенное количество ТНК оперирует в традиционном торговом секторе, в целом международные фирмы выступают за промышленную реструктуризацию многих развивающихся стран путем создания новых отраслей, в частности, автомобильной, нефтехимической, машиностроительной, электронной и др., и модернизации традиционных, включая текстильную и пищевую.

Так, важнейший аспект влияния глобализации на национальную экономику касается влияния на технологические инновации. Новые технологии, как уже отмечалось, являются одной из движущих сил глобализации, но она, в свою очередь усиливая конкуренцию, стимулирует их дальнейшее развитие и распространение среди стран.

Таким образом, глобализация повлияла на формирование такой предпосылки развития интрапренерства, как обострение международной конкуренции. Конкуренция и расширение рынка ведут к углублению специализации и международно-

\section{Baikal Research Journal}

электронный научный журнал Байкальского государственного университета 
го разделения труда, стимулирующих в свою очередь рост производства не только на национальном, но и на мировом уровне.

Результатом углубления интернационализационного процесса являются взаимозависимости и взаимодействия национальных экономик. Это можно воспринимать и интерпретировать как интеграцию государств в структуру, близкую к единой интернациональной экономической системе. Национальное развитие все более увязывается с глобальными структурами и становится более многосторонним и разноплановым, чем это было в прошлом, хотя основная часть глобального продукта все же потребляется в странах-производителях. Таким образом, важнейшей предпосылкой возникновения интрапренерства как формы взаимодействия малого и крупного бизнеса на мезоуровне является поиск конкурентных преимуществ для целых отраслей национальной экономики ${ }^{2}$.

Важнейшей предпосылкой развития интрапренерства на микроуровне является потребность в новаторстве, инициативах и нововведениях. Интрапренерство позволяет синтезировать инновационное поведение, предприимчивость и передовые технологии субъектов малого бизнеса с каналами распределения продукции и маркетинговой, финансовой мощью крупного предприятия, что порождает значительное конкурентное преимущество.

Таким образом, можно отметить, что предпосылки в технико-экономической сфере на всех уровнях сводятся, главным образом, к необходимости обеспечения в компании, отрасли и национальной экономике страны конкурентных преимуществ.

Так, диктуемые предпосылками в разных сферах общественной жизни, сформировались предпосылки в сфере государственного регулирования. Развитие малого и среднего бизнеса - одно из важнейших направлений государственной политики в сфере экономики, на которое возлагаются большие надежды. Так, взаимодействие малого бизнеса с крупным - это обусловленная необходимость, целью которой является качественное укрепление экономики страны.

Интрапренерство как форма взаимодействия малого и крупного бизнеса может решить ряд проблем, возникающих в процессе деятельности как малых, так и крупных компаний.

Можно выделить следующие основные, на наш взгляд, преимущества реализации проектов в малом бизнесе, которые, очевидно, будут существенно влиять на эффективность функционирования крупного бизнеса при внедрении в компаниях основ интрапренерства:

1. По сравнению с проектами, реализуемыми на крупных предприятиях, проекты в малом предпринимательстве требуют меньших финансовых вложений, что позволяет увереннее подходить к их разработке и дальнейшей реализации.

2. Сравнительно невысокие издержки управления, в связи с отсутствием необходимости в большом количестве контролирующих работников. Это позволяет управлять проектами более гибко, дает возможность оперативно реагировать на изменения в процессе их реализации. В субъектах малого бизнеса целесообразно и достаточно проведение внутреннего аудита, организованного бизнесом в интересах собственников и руководства [8].

3. Так как проекты в малом предпринимательстве, как правило, не слишком масштабны, они имеют свойство оперативно реагировать на изменяющиеся условия и быстро адаптироваться к ним.

4. Так как малые предприятия чаще работают на локальных рынках, у них есть возможность постоянно контролировать требования на местном уровне и бы-

${ }^{2}$ Глобализация мировой экономики. URL: http://www.grandars.ru/college/sociologiya/globalizaciya.html.

\section{Baikal Research Journal}

электронный научный журнал Байкальского государственного университета 
стро корректировать реализуемые проекты и производимую продукцию в ответ на изменяющийся спрос, чего, очевидно не достает крупным компаниям.

5. Проекты реализуются в более короткие сроки, чем проекты в крупном бизнесе. Это позволяет добиваться достаточно коротких сроков окупаемости.

6. Работники, участвующие в разработке и реализации проектов в малом предпринимательстве имеют большую мотивацию и вовлеченность в деятельность, чем в крупном бизнесе, что способствует улучшению производительности труда. Это достигается прежде всего благодаря небольшому количеству участников проекта и значимости каждого из них.

Также можно выделить ряд недостатков реализации проектов в малом бизнесе, которые будут без труда устранены с помощью возможностей крупных компаний после внедрения интрапренерства:

1. Главным недостатком проектов в малом предпринимательстве является высокий уровень их риска. Об этом говорит большое количество не реализованных или плохо реализованных проектов. Важно отметить, что данный показатель в крупном бизнесе значительно ниже, а значит проекты в малом предпринимательстве отличаются серьезной неустойчивостью.

2. Низкая проработанность проектов - еще один серьезный недостаток. Несмотря на заинтересованность работников в удачной реализации проекта, часто происходит, что команда проекта не может сработаться и возникает недоговоренность, которая затрудняет их совместную работу.

Совмещение интересов самой компании, коллектива сотрудников и каждого работника в частности при планировании карьеры обычно начинается с понимания того, что каждый представляет собой три уровня управления: во-первых, уровень управления компанией как целостной системой, во-вторых, уровень управления группами (как неформальными, так и формальными) и их взаимодействие, и, в-третьих, уровень управления исполнителями. Так, все три уровня должны одновременно сосуществовать в системе управления человеческими ресурсами, и соответственно, должны являться продолжением друг друга [9, с. 1].

3. Из предыдущего недостатка можно вывести еще один - высокая вероятность конфликтности и несогласованности команды проекта. Часто это вызвано тем, что коллектив работников создается спонтанно, каждый выполняет свои функции, не оговаривая их с руководителем проекта и тем более с коллегами. Также этот недостаток проявляется в связи с тем, что малые предприятия, как правило, уделяют мало внимания сплочению коллектива, не занимаются созданием необходимой психологической среды в коллективе. Крупные же предприятия периодически проводит семинары, тренинги и прочие мероприятия по улучшению взаимоотношений в кругу сотрудников.

Так, проблемы, появляющиеся в современных условиях, требуют от руководства хозяйствующего субъекта непрерывной социально-психологической работы с сотрудниками. Администрация компании должна иметь грамотно разработанную программу стабилизации коллектива, который должен эффективно работать не только в периоды обострений кризисов, но и, на опережение, формируя, как следствие, однонаправленный сплоченный солидарный коллектив [10, с. 36]. В данной ситуации будет уместна активная или превентивная кадровая политика в компании. При превентивной политике руководство владеет обоснованными прогнозами развития кадровой ситуации в компании на средне- и краткосрочный периоды, также предлагается ряд мероприятий по развитию персонала. В свою очередь, при активной политике руководство обладает обоснованными прогнозами развития компании и соответствующим инструментарием влияния на сотрудников. В компаниях, реализующих активную кадровую политику, разрабатываются антикризис-

\section{Baikal Research Journal}

электронный научный журнал Байкальского государственного университета 
ные программы, систематически проводится мониторинг ситуации, далее данные программы корректируются с учетом воздействия внешней и внутренней среды. Так, эффективность кадровой политики компании возрастет, если будут определены результаты новшеств для каждого сотрудника в отдельности и пути достижения оптимального состояния кадрового потенциала компании [11, с. 2640$].$

4. Как уже было сказано ранее, по сравнению с проектами, реализуемыми на крупных предприятиях, проекты в малом предпринимательстве требуют меньших финансовых вложений. Однако несмотря на необходимость небольшого количества вложений существует сложность в привлечении данных средств. Для разработки проектов малого предпринимательства большой проблемой является получение кредитов и привлечение потенциальных инвесторов. Важные вопросы, возникающие при принятии решений об инвестировании, - это вопрос о потенциальной выгодности вложений и вопрос о поиске направлений инвестирования. Решающими факторами в решении данных вопросов являются склонность инвестора к возникающим рискам, величина имеющихся средств для вложений, условия деятельности, цели инвестирования, экономические и прочие интересы, определяющие его инвестиционное поведение и пр. Решающим фактором, важно заметить, при этом выступают складывающиеся макроэкономические условия, от совокупности которых в итоге зависит выгодность инвестиционных вложений [12, с. 29].

Одной важной особенностью проектов малого предпринимательства является их инновационность. В западных странах уже давно для реализации таких проектов создаются специальные экономические, правовые и социальные условия. В России такая практика применяется не часто, только на уровне субсидий и ряда социальных программ. Сегодня делается ставка на государственную поддержку через банковский сектор. Она осуществляется посредством выделения микрозаймов, субсидирования ставок малому и среднему бизнесу, а также путем предоставления грантов безработным и начинающим бизнесменам. Однако, отметим, что количество желающих участвовать в муниципальных и региональных программах ничтожно мало [13, с. 5].

У российских компаний малого предпринимательства в последние годы наметился ряд проблем, связанных с ведением и организацией проектного управления. Одной из проблем является использование программных продуктов. В большинстве своем они создаются для использования крупными и средними компаниями, которые имеют возможность их приобрести и обслуживать их использование. Малым же предприятиям приходится приобретать дешевые программные продукты, которые подходит только для проектного управления в одном или нескольких подразделениях предприятия. Соответственно для реализации проекта необходимо приобретение нескольких разных продуктов, использование которых приводит к несогласованности работы подразделений предприятия, создает проблемы в их взаимодействии, что в свою очередь, приводит к отставанию по срокам, невыполнению ряда задач, удорожанию проекта и т.д. Еще одной проблемой является сложность адаптации предприятий к проектным методологиям систем управления проектами, применяемым как на западе, так и в России. Проблема адаптации обусловлена как внешними, так и внутренними факторами. Ориентация на западный опыт и использование систем управления проектами западной разработки являются внешними факторами. $К$ внутренним относится, например, отсутствие опыта работников и недостаточная квалификация управленческого персонала в управлении проектами. Крупные компании, в свою очередь, также сталкиваются с рядом сложностей при разработке проектов.

Исходя из изложенного, можно сделать вывод, что на сегодняшний день в России сформировался полный комплекс предпосылок внедрения внутрифирмен-

\section{Baikal Research Journal}

электронный научный журнал Байкальского государственного университета 
ного предпринимательства. Социальная и экономическая сферы бизнеса в нашей стране пребывают в состоянии, требующем существенных изменений, касающихся оптимизации организационно-хозяйственных процессов в компаниях, повышения эффективности бизнеса, своевременной обеспеченности компаний необходимыми ресурсами, минимизации потерь от реализации высокорисковых проектов, обеспечения должного уровня мотивации работников и др. Так, интрапренерство как форма взаимодействия малого и крупного бизнеса, позволит решить большое количество сложностей, возникающих в компаниях из-за существенной нехватки того или иного ресурса, а также, очевидно, сможет положительным образом повлиять на различные сферы общественной жизни.

\section{Список использованной литературы}

1. Pinchot G. Intrapreneuring: Why You Don't Have to Liave the Company to Become an Entrepreneur / G. Pinchot. - New York : Harper and Row, 1985. - 380 p.

2. Багиев Г. Л. Организация предпринимательской деятельности : учеб. пособие / Г. Л. Багиев, А. Н. Асаул ; под ред. Г. Л. Багиева. - СПб. : Изд-во СПбГУЭФ, 2001. - 231 с.

3. Чистякова О. В. Инновационные аспекты повышения конкурентоспособности предпринимательских структур : монография / О. В. Чистякова. - Иркутск : Изд-во БГУЭП, 2011. -204 c.

4. Хизрич Р. Предпринимательство или Как завести собственное дело и добиться успеха. В 5-ти вып. / Р. Хизрич, М. Питерс ; под ред. В. С. Загащвили. - М. : Прогресс-Универс, 1992. - Вып. 5 : Советы начинающему предпринимателю. - 192 с.

5. Шапиро С. А. Социально-экономические аспекты трудовой деятельности : монография / С. А. Шапиро. - М. : АТИСО. - 2011. - 254 с.

6. Якимов В. Н. Стимулирование и мотивация труда в организации / В. Н. Якимов // Знание. Понимание. Умение. - 2012. - № 4. - С. 61-67.

7. Дудов А. С. Социальная инфраструктура предприятий в современных условиях [Электронный ресурс] / А. С. Дудов // Управление экономическими системами: электронный научный журнал. - 2013. - № 12 (60). - Режим доступа: http://uecs.ru/uecs60602013/item/2708-2014-01-22-08-54-22.

8. Шохнех А. В. И нет им покоя... особенности организации системы внутреннего контроля в субъектах малого бизнеса / А. В. Шохнех // Российское предпринимательство. 2008. - № 1. - С. 158-162.

9. Зайцева Т. В. Совмещение интересов организации, коллектива и работников при планировании карьеры [Электронный ресурс] / Т. В. Зайцева // Государственное управление. Электронный вестник. - 2012. - № 30. - С. 1-10. - Режим доступа: http://ejournal.spa.msu.ru/vestnik/ item/30_2012zajceva.htm.

10. Сметанин В. Социальная психология в помощь кадровикам / В. Сметанин // Справочник по управлению персоналом. - 2010. - № 8. - С. 33-43.

11. Алехина Л. Л. Влияние социально-психологических факторов на формирование личности в коллективе работников организации в условиях нестабильности / Л. Л. Алехина, И. В. Ильин // Фундаментальные исследования. - 2015. - № 2. - С. 2637-2641.

12. Хомкалов Г. В. Инвестирование в недвижимость в условиях экономического кризиса / Г. В. Хомкалов, Н. Ю. Ковалевская // Актуальные тенденции развития мировой экономики : материалы междунар. науч.-практ. конф. : в 2 т. - Иркутск : Изд-во БГУ, 2016. - T 2. -C. 29-36.

13. Гавряшина Ю. В. Развитие малого бизнеса в россиив условиях кризиса / Ю. В. Гавряшина, Е. М. Жердева // Стратегии бизнеса. - 2015. - № 11. - С. 3-10.

\section{References}

1. Pinchot G. Intrapreneuring: Why You Don't Have to Liave the Company to Become an Entrepreneur. New York, Harper and Row, 1985. 380 p.

2. Bagiev G. L., Asaul A. N.; Bagieva G. L. (ed.). Organizatsiya predprinimatel'skoi deyatel'nosti [Organization of entrepreneurial activity]. Saint Petersburg State University of Finance and Economics Publ., 2001. 231 p.

\section{Baikal Research Journal}


3. Chistyakova O. V. Innovatsionnye aspekty povysheniya konkurentosposobnosti predprinimatel'skikh struktur [Innovation aspects of improving business competitiveness]. Irkutsk, Baikal State University of Economics and Law Publ., 2011. 204 p.

4. Hisrich Robert D., Peters Michael P. Entrepreneurshhip : Starting, developing, and managing a new enterprise. Homewood, Richard D Irwin, INC., 1989. 650 p. (Russ. ed.: Khizrich R., Piters, M.; Zagashchvili V. S. (ed.) Predprinimatel'stvo ili Kak zavesti sobstven-noe delo i dobit'sya uspekha. Moscow, Progress-Univers Publ., 1992, iss. 5. Sovety nachinayushchemu predprinimatelyu. 192 p.).

5. Shapiro S. A. Sotsial'no-ekonomicheskie aspekty trudovoi deyatel'nosti [Socio-economic aspects of work activity]. Moscow, Academy of labour and social relations, 2011. $254 \mathrm{p}$.

6. Yakimov V. N. The Encouragement and Motivation of Labour in Organization. Znanie. Ponimanie. Umenie. $=$ Knowledge. Understanding. Skill, 2012, no. 4, pp. 61-67. (In Russian).

7. Dudow A. S. Social infrastructure of enterprises in modern conditions. Management of Economic Systems. Scentific electronic journal, 2013, no. 12 (60). Available at: http://uecs. ru/uecs60-602013/item/2708-2014-01-22-08-54-22.

8. Shokhnekh A. V. Peculiarities of Internal Control in Small Businesses. Rossiiskoe predprinimatel'stvo = Russian Journal of Entrepreneurship, 2008, no. 1, pp. 158-162. (In Russian).

9. Zaytseva T.V. Combination of Interests of Organization, Collective and Employees in Career Development. Public Administration. E-Journal, 2012, no. 30, p. 1-10. Available at: http://e-journal.spa.msu.ru/vestnik/ item/30_2012zajceva.htm.

10. Smetanin V. Social psychology in aid of personnel officers. Spravochnik po upravleniyu personalom = Staff Management Handbook, 2010, no. 8, pp. 33-43. (In Russian).

11. Alekhina L L, Ilin I V. The Influence of Socio-Psychological Factors on the Personality's Formation in the Collective of the Organization in Unstable Conditions. Fundamental'nye issledovaniya = Fundamental research, 2015, no. 2, pp. 2637-2641. (In Russian).

12. Khomkalov G V, Kovalevskaya N Yu. Investing in real estate in the context of economic crisis. Aktual'nye tendentsii razvitiya mirovoi ekonomiki [Current trends in development of world economy. Materials of International Research Conference]. Irkutsk, Baikal State University, 2016, vol. 2, pp. 29-36. (In Russian).

13. Gavryashina Yu. V., Zherdeva E. M. The Development pf Small Business in Conditions of Crisis in the Russian Federation. Strategii biznesa = Business Strategies, 2015, no. 11, pp. 3-10. (In Russian).

\section{Информация об авторе}

Гусева Галина Викторовна - аспирант, кафедра экономики предприятия и предпринимательской деятельности, Байкальский государственный университет, 664003, г. Иркутск, ул. Ленина,11, e-mail: galiguseva@yandex.ru.

\section{Author}

Galina V. Guseva - Post-Graduate Student, Chair of Economics of Enterprise and Entrepreneurship, Baikal State University, 11 Lenin St., 664003, Irkutsk; e-mail: galiguseva@ yandex.ru.

\section{Для цитирования}

Гусева Г. В. О сущности интрапренерства и необходимости его развития в условиях глобализации / Г. В. Гусева // Baikal Research Journal. - 2017. - T. 8, № 4. - DOI : 10.17150/2411-6262.2017.8(4).21.

\section{For Citation}

Guseva G. V. On the matter of entrepreneurship and the need for its development in the context of globalization. Baikal Research Journal, 2017, vol. 8, no. 4. DOI: 10.17150/24116262.2017.8(4).21. (In Russian).

\section{Baikal Research Journal}

